\title{
RODA DE CONVERSA ENTRE MULHERES: DENÚNCIAS SOBRE A LEI MARIA DA PENHA E DESCRENÇA NA JUSTIÇA
}

\author{
Márcia Santana Tavares \\ Universidade Federal da Bahia
}

\begin{abstract}
Resumo: Este artigo discute os desafios para a aplicação da Lei Maria da Penha em Salvador, Bahia, a partir do depoimento de onze mulheres em situação de violência doméstica e familiar, cujas queixas e demandas sobre a rede de atendimento foram verbalizadas em uma Roda de Conversa, realizada no Conselho de Desenvolvimento da Comunidade Negra (CNDN) em 5 de junho de 2012, para subsidiar a elaboração de um dossiê a ser entregue à CPMI da Violência, durante suas diligências na Bahia. As mulheres consideram o atendimento insatisfatório, tanto nas DEAMs como na Vara, no Ministério Público, no IML e até no Disque 190, uma vez que suas demandas não são atendidas. Sentem-se desprotegidas, humilhadas, desrespeitadas e reféns das situações de violência que as levam a peregrinar por estas instituições.

Palovras-chave: violência contra as mulheres; Lei Maria da Penha; acesso à justiça.
\end{abstract}

\section{Notas iniciais}

A violência de gênero contra mulheres é um fenômeno recorrente nas sociedades contemporâneas, identificado em várias partes do mundo, atinge mulheres de diferentes classes sociais, faixas etárias, castas, raças e etnias, embora nem sempre seja visível ou considerado como um problema social. No entanto, desde as últimas décadas do século $X X$, a violência doméstica e familiar, em especial, tem sido alvo de estudos que buscam conferir visibilidade e compreender esse fenômeno, e também refletir sobre os serviços públicos e as políticas de enfrentamento.

No Brasil, de acordo com Cecília MacDowell Santos, ${ }^{1}$ a violência doméstica e familiar contra a mulher permaneceu oculta entre quatro paredes até a década de 1970 . Tanto o Estado como a sociedade em geral não a reconheciam como um problema social e

Copyright (C) 2015 by Revista Estudos Feministas.

${ }^{1}$ Cecília MacDowell SANTOS, 2010. 
político, nem tampouco como uma questão de saúde pública, sendo coniventes com essa prática social, por considerá-la como uma questão de ordem privada e "normal".

A politização da violência doméstica e familiar ocorreu a partir do ano de 1975, aclamado pela Organização das Nações Unidas como "Ano Internacional da Mulher", que inaugurou a "Década da Mulher" (1975-1985), suscitando a intensificação do debate sobre o tema na sociedade, desde a realização de campanhas, publicação de reportagens em jornais e revistas, exibição de seriados televisivos. No período em questão, recorda Maria Filomena Gregori, ${ }^{2}$ foram implantados os primeiros serviços de atendimento às mulheres em situação de violência, como por exemplo, o SOS Mulher, em 1980, primeiro grupo a combater a violência e a prestar serviços de orientação jurídica às mulheres. Eva Alterman Blay ${ }^{3}$ acrescenta a criação do Conselho Estadual da Condição Feminina, em 1983, concentrado em quatro áreas de ação, creche, trabalho, violência e saúde; o Conselho Nacional de Direitos das Mulheres (CNDM) e a primeira Delegacia da Mulher (DDM), em 1985, cujo principal objetivo era reprimir a violência contra as mulheres.

No contexto de redemocratização do país e de redação da Carta Magna, os movimentos feministas e de mulheres, sob a condução do CNDM, articularam-se e lançaram a campanha nacional "Constituinte para valer tem que ter direitos da mulher". Essa campanha culminou com a elaboração de propostas, sistematizadas na Carta das Mulheres à Assembleia Constituinte, documento que respaldou uma ação direta de convencimento junto aos parlamentares, tendo como resultado a aprovação de $80 \%$ das demandas apresentadas pelo movimento na Constituição Federal de 1988 que, finalmente, formaliza a cidadania plena das mulheres e o seu direito a uma vida sem violência.

Lourdes Bandeira ${ }^{4}$ pontua que, na década seguinte - a chamada década das conferências -, o Brasil não só participou como foi signatário das deliberações das Conferências promovidas pela ONU no Cairo (1994) e Beijing (1995), assim como da Conferência Mundial de Direitos Humanos, realizada em Viena (1993), evento no qual a violência de gênero contra mulheres foi reconhecida como uma violação dos direitos humanos das mulheres. Todavia, cabe mencionar que, embora o Protocolo Opcional à Convenção sobre a Eliminação de Todas as Formas de Discriminação contra a Mulher (Cedaw, 1979) contemple a violência doméstica e sexual contra as mulheres, esta apenas se torna foco de discussão na Declaração sobre a Eliminação da Violência contra a Mulher (1993) e na Convenção Interamericana para Prevenir, Punir e Erradicar a Violência contra a Mulher (1994), mais conhecida como Carta de Belém do Pará.

Conforme Leila Linhares Barsted, ${ }^{5}$ em 1995, foi sancionada a Lei no 9.099/95, que instituiu os Juizados Especiais Cíveis e Criminais (Jecrims), com o intuito de tornar ágil o acesso à justiça, no caso de conflitos de natureza penal, classificados como crime de menor potencial ofensivo. Todavia, o cumprimento da referida Lei mostrou-se um equívoco, pois diante da maioria das denúncias feitas nas Delegacias Especializadas de Atendimento à Mulher (DEAMs) - lesões corporais leves e ameaças -, recomendava-se a conciliação entre as partes e a aplicação de multas como medida de reparação aos danos causados, geralmente o pagamento de cestas básicas. Deste modo, ressalta Sílvia de Aquino, ${ }^{6}$ a violência não era criminalizada e os agressores permaneciam como réus primários, isso porque, de acordo com Fernanda Marques de Queiroz, ${ }^{7}$ os conciliadores desconsideravam

\footnotetext{
${ }^{2}$ Maria Filomena GREGORI, 1993.

${ }^{3}$ Eva Alterman BLAY, 2003.

${ }^{4}$ Lourdes BANDEIRA, 2005.

${ }^{5}$ Leila Linhares BARSTED, 2007.

${ }^{6}$ Sílvia de AQUINO, 2008.

7 Fernanda Marques de QUEIROZ, 2008.
} 
as relações de gênero assimétricas que produzem e alimentam os conflitos, assim como o caráter cíclico que retrata a violência contra a mulher.

Assim, para a perspectiva feminista, ao invés de promover avanços, a referida Lei $\mathrm{n}^{\circ}$ 9.099/95 gerou um retrocesso no enfrentamento à violência contra a mulher, opinião explicitada em debates e protestos contra os Jecrims que, após uma década, resultaram na formação de um consórcio de organizações não governamentais e advogadas especialistas na temática, responsável pela elaboração de uma proposta de lei que revogasse a competência dos Jecrims para julgar os casos em sua alçada.

Conforme lembram Cecilia Sardenberg, Márcia Santana Tavares e Márcia Gomes, ${ }^{8}$ a minuta de um projeto de lei foi entregue à deputada Jandira Feghali, no Congresso Nacional e encaminhada ao Executivo Federal, através da Secretaria Especial de Políticas para Mulheres, implantada pelo presidente Lula. Uma comissão interministerial, constituída pelo governo e por feministas integrantes das ONGs e redes, elaborou a minuta original da lei, que foi aprovada pelo Congresso e assinada pelo presidente em 7 de agosto de 2006. A Lei de Enfrentamento à Violência Doméstica e Familiar contra a Mulher (Lei n 11.340), ${ }^{9}$ mais conhecida como Lei Maria da Penha, entrou em vigor no mês de setembro do mesmo ano.

Em suma, o processo de institucionalização das demandas dos movimentos feministas e de mulheres para coibir a violência contra as mulheres é representado por três momentos emblemáticos: inicialmente, a implantação das delegacias da mulher, em meados dos anos 1980; em segundo lugar, a criação dos Juizados Especiais Criminais, em meados da década seguinte e, finalmente, a sanção da Lei $n^{\circ} 11.340$, em 2006, popularmente conhecida como Lei Maria da Penha. ${ }^{10}$

A Lei Maria da Penha trouxe significativos avanços no que se refere à proteção social das mulheres em situação de violência e traz, de acordo com Flávia Piovesan e Sílvia Pimentel, inovações significativas:

[...] mudança de paradigma no enfrentamento da violência contra a mulher incorporação da perspectiva de gênero para tratar da desigualdade e da violência contra a mulher; incorporação da ótica preventiva, integrada e multidisciplinar; fortalecimento da ótica repressiva; harmonização com a Convenção Cedaw/ONU e com a Convenção Interamericana para Prevenir, Punir e Erradicar a Violência contra a Mulher; consolidação de um conceito ampliado de família e visibilidade ao direito à livre orientação sexual; e, ainda, estímulo à criação de bancos de dados e estatísticas."

De fato, podemos identificar no texto da Lei não só mudanças de caráter conceitual, como prescrições que politizam e criminalizam a violência contra a mulher, mas também determinações de criação de serviços de proteção social para as mulheres em situação de violência. Neste sentido, Tavares, Sardenberg e Gomes destacam as seguintes inovações na Lei Maria da Penha: ${ }^{12}$

a) define e caracteriza a violência doméstica e familiar contra a mulher, em consonância com as considerações das convenções internacionais;

b) classifica as modalidades de violência doméstica contra a mulher - física, psicológica, sexual, patrimonial e assédio moral;

c) elimina as penas pecuniárias, pagas com cesta básicas ou multas;

${ }^{8}$ Cecilia SARDENBERG, Márcia Santana TAVARES e Márcia Q. de C. GOMES, 2012.

9 BRASIL, 2006.

10 SANTOS, 2010

11 Flávia PIOVESAN e Sílvia PIMENTEL, 2007, p. 1.

12 TAVARES, SARDENBERG e GOMES, 2011. 
d) reconhece que a violência doméstica independe da orientação sexual;

e) retira dos juizados especiais a competência para apreciar os crimes de violência doméstica contra a mulher;

f) determina a criação de juizados especiais de violência doméstica e familiar contra a mulher, com competência cível e criminal para tratar das questões familiares decorrentes da violência contra a mulher;

g) altera o código do processo penal de modo que o juiz possa decretar a prisão preventiva diante de riscos à integridade física ou moral da mulher;

h) permite a prisão do agressor, em caso de flagrante;

i) aumenta a pena do crime de violência doméstica de três meses para três anos;

j) altera a lei de execuções penais para possibilitar que o juiz prescreva o comparecimento obrigatório do agressor a programas de educação e reabilitação.

Um dos instrumentos instituídos pelo Governo Federal para assegurar a implementação da Lei Maria da Penha foi o lançamento do Pacto Nacional pelo Enfrentamento à Violência contra a Mulher. ${ }^{13}$ Coordenado pela Secretaria Especial de Políticas para as Mulheres (SPM), o Pacto Nacional visa prevenir e enfrentar as diversas formas de violência contra as mulheres, através da execução de um conjunto de políticas públicas intersetoriais, cujas ações vêm sendo implementadas por ministérios e secretarias especiais, nas várias esferas da vida social. Mais especificamente, traz como um de seus objetivos a redução dos índices de violência contra as mulheres, para a qual é fundamental a consolidação da Política Nacional de Enfrentamento à Violência contra as Mulheres, que propõe ações voltadas para a implementação da Lei Maria da Penha, dentre as quais o monitoramento da aplicação da Lei, realizado pelo Observatório de Monitoramento da Lei Maria da Penha (Observe).

O Observe é uma instância autônoma, da sociedade civil, formado por um consórcio que agrega organizações não governamentais e núcleos de pesquisa universitários. Instalado em 2007, o Observe é liderado pelo Núcleo de Estudos Interdisciplinares sobre a Mulher (NEIM), da Universidade Federal da Bahia (UFBA) e tem como missão monitorar o processo de implementação e aplicação da Lei Maria da Penha, mediante a coleta, análise e publicização de informações do processo de efetivação da Lei em todo o país. ${ }^{14}$

Desde sua implantação, o Observe tem desenvolvido várias atividades, desde: elaboração de uma metodologia para monitorar a efetiva aplicabilidade da Lei e seu impacto ao longo do tempo e em diferentes espaços territoriais; capacitação de pesquisadoras para realização do monitoramento da Lei; estudos de caso em algumas capitais brasileiras; pesquisas sobre as condições reais de aplicação da Lei Maria da Penha nas DEAMs e nos Juizados de Violência Doméstica e Familiar das capitais brasileiras e do Distrito Federal, e também sobre acesso das mulheres à justiça no Brasil.

Mais recentemente, desenvolvi a pesquisa intitulada $A$ implementação da Lei Maria da Penha e o acesso das mulheres à Justiça em Salvador/BA, financiada pelo CNPq, com o intuito de investigar o processo de implementação da Lei no estado da Bahia, a partir do ponto de vista dos executores da política de enfrentamento à violência contra a mulher nas DEAMs e das mulheres em situação de violência que buscam os serviços de proteção e apoio. Dentre as atividades desenvolvidas durante a pesquisa empírica, participei de

${ }^{13}$ BRASIL, 2007. O Pacto foi lançado pelo presidente Lula na cerimônia de abertura da II Conferência Nacional de Políiticas para as Mulheres, realizada em 17 de agosto de 2007.

${ }^{14} \mathrm{O}$ Observatório de Monitoramento da Lei Maria da Penha dispõe de um Portal, < www.observe.ufba.br >, no qual são compartilhados notícias e artigos científicos nacionais e regionais, a legislação vigente e documentos referentes a convenções/pactos internacionais, além de resultados de pesquisas e outras informações acerca da violência contra a mulher. 
uma Roda de Conversa em Salvador, com mulheres em situação de violência doméstica e familiar, sobre a qual me deterei nos próximos tópicos.

\section{Caminhos metodológicos}

A Roda de Conversa é uma modalidade de metodologia participativa comumente utilizada quando se pretende promover uma cultura de reflexão sobre os direitos humanos. Para tanto, busca-se estimular a participação e a reflexão, ou seja, o diálogo entre os participantes é incentivado mediante a adoção de uma postura de escuta e a circulação da palavra, bem como o uso de dinâmicas de grupo conduzidas por um(a) facilitador(a). Em suma, Maria Lúcia M. Afonso e Flávia Abade assim definem a Roda de Conversa: "É uma proposta dialógica que visa relacionar cultura e subjetividade". ${ }^{15}$

A Roda de Conversa em Salvador foi realizada no Conselho de Desenvolvimento da Comunidade Negra do Estado da Bahia (CNDN), em 05 de junho de 2012, para subsidiar a elaboração de um dossiê a ser entregue à Comissão Parlamentar de Inquérito da Violência contra as Mulheres, a CPMI da Violência, durante suas diligências na Bahia. Na ocasião, foi decidido que o dossiê deveria incluir depoimentos de usuárias da rede sobre os serviços de atenção, além dos dados disponibilizados pelos órgãos oficiais. A Roda teve como participantes onze mulheres em situação de violência doméstica e familiar, encaminhadas por serviços da Rede de Atendimento e por movimentos sociais, bem como algumas representantes de entidades que integram o GT da Rede de Atenção às Mulheres em Situação de Violência de Salvador, ${ }^{16}$ tendo-se o cuidado de excluir aquelas dos segmentos profissionais vinculados aos serviços, de modo a evitar possíveis inibições e/ou constrangimentos entre as usuárias.

Inicialmente, foi aplicada uma técnica de relaxamento e integração do grupo, na qual a facilitadora procurou deixar as mulheres mais fortalecidas e confiantes para narrarem sua história, os caminhos percorridos para romperem com a violência doméstica e familiar, falarem sobre o que lhes aconteceu quando decidiram dar um basta e, como foi o atendimento nos serviços a que recorreram.

Conforme ressaltam Afonso e Abade, a sensibilização é um momento crucial, uma vez que evoca lembranças, sentimentos e ideias. E, se for feita de maneira compartilhada no grupo, traz melhores resultados. Assim, as cadeiras foram agrupadas em círculo e, ao som de uma música instrumental e da provocação olfativa de um incenso, as mulheres foram convidadas a mergulharem em seu mundo interior e, de olhos cerrados, resgatarem sua trajetória, desde o momento em que recorreram aos órgãos responsáveis pelo atendimento a mulheres em situação de violência, enquanto a facilitadora as questionava: "Onde foram buscar ajuda? Quais as facilidades e/ou dificuldades encontradas? O que falta nessas instituições/serviços?"

Após alguns minutos, a facilitadora incentivou as mulheres a utilizarem hidrocores e lápis de cera e, em uma folha de papel sulfite, registrarem uma frase e/ou desenho que expressasse os caminhos percorridos nessa trajetória, deixando-as livres para se deslocarem e/ou se afastarem do grupo naquele momento, caso se sentissem mais à vontade para

${ }^{15}$ Maria Lúcia M. AFONSO e Flávia ABADE, 2008, p. 19.

${ }^{16} \mathrm{O}$ GT da Rede de Atenção às Mulheres em Situação de Violência de Salvador e Região Metropolitana, existente há 12 anos, é um coletivo formado por ativistas dos movimentos feministas e de mulheres que trabalham em serviços de atendimento a mulheres em situação de violência, gestoras de organismos de políticas para as mulheres, estagiárias, estudantes e professoras que integram núcleos de pesquisa da universidade, assessoras de mandatos legislativos nas três esferas de governo - municipal, estadual e federal -, bem como representantes em conselhos de direitos ou de categorias profissionais. 
organizarem as ideias. Após cerca de dez minutos, a facilitadora pediu que retornassem a seus lugares e, munida de um bastão, instruiu as mulheres: "Quem quiser falar, pega o bastão e, enquanto estiver com ele na mão tem a palavra, até passar para a próxima que quiser falar". Enfim, foi-Ihes solicitado que se apresentassem e compartilhassem sua história. "Quem quer começar?"

\section{A violência na Roda: entre queixas e demandas}

Os depoimentos acerca do atendimento nos serviços são entremeados por lágrimas, silêncios e pausas, e também por uma desordem no tempo cronológico, recurso escatológico utilizado pelas mulheres para resgatarem dores e temores, reconstituírem acontecimentos $e$ desnudarem seus sentimentos em relação aos serviços: ${ }^{17}$

[...] desde 2010 venho lutando, porque meu ex-marido me agrediu, eu convivi com ele 16 anos, me agredia sempre, [...] já me violentou várias vezes, e aí denunciei ele [...] para a DEAM, chegando lá, a delegada [...] ela falou: 'Olhe, $X$, volte para ele, porque ele te ama muito ainda, ele disse que não fez nada com você não'. E essa queixa que eu dei? E o que eu fui fazer corpo delito, fica aonde? [...] veio a medida protetiva, corri muito atrás também, [...] da $1^{a}$ Vara para cá, de hoje que estou lutando, tive três audiências, ele já foi intimado e nunca compareceu, [...] tem três prisões preventivas dele, nunca foi preso [...]. Dra. A.: 'Eu já mandei a prisão preventiva dele, ele vai ser preso'. Esperei, aguardei e nada. Retornei lá. 'Nada ainda?' Eu: 'Não'. Quem entrega intimação? No oficial de justiça, não achei oficial de justiça nenhum. Ninguém sabia se entregou ou não a intimação para ele [...]. E assim eu acho que precisa melhorar bastante, sabe? A $1^{a}$ Vara da Justiça, porque está horrível. (Amora)

[...] o primeiro passo que eu fiz foi procurar a DEAM, quando chegou lá, porque eu não me separava, pediu a medida protetiva, mandou para a Vara, na Vara nunca mandou o oficial. E eu indo lá. Saindo do trabalho, pedindo para ir. Chegava lá, diziam que era porque não tinha oficial suficiente para entregar. Hoje já estamos em 2012, aí o resultado: perderam meu processo, meu marido nunca foi ouvido. A gente tinha uma casa no interior, no Engenho Velho, aí aconteceu que em 2010 eu tive que sair de casa às pressas, fui morar na casa de uma colega até construir uma casa escondida [...]. Quando agora ela me disse que tinha perdido o processo, eu desisti, fiquei triste. Foi uma caminhada perdida, aí eu perguntei o que é justiça, porque ele nunca foi ouvido lá, [...] na DEAM. Eu não vou mais lá, porque eu já fui três vezes, e na Vara, [...]. Como ela perdeu [o processo]? (Malu)

Na Delegacia nós temos um primeiro problema, por mais que nós tenhamos um delegado, nós temos pouco, se não me engano, só duas DEAMs aqui em Salvador. Nas Delegacias da Mulher, as pessoas que redigem a queixa não estão preparadas para redigir a queixa... Não contei com advogados, por conta da parte financeira. Nós temos um déficit de defensores públicos no nosso Estado, nós só temos uma defensora na Vara, que só atua na parte de medida protetiva, não obrigatoriamente na parte penal, que é o que a gente precisa, e geralmente os processos não se finalizam, e isso causa na gente uma violência maior... Meu processo ficou parado três meses porque a prioridade era alvará de soltura. Mas a gente pode esperar meses e anos sem uma medida protetiva, sem uma proteção, eu preciso de justiça. (Sílvia)

\footnotetext{
${ }^{17}$ Os nomes das mulheres são fictícios, extraídos de personagens de novelas televisivas, de modo a preservar seu anonimato.
}

552 Estudos Feministas, Florianópolis, 23(2): 547-559, maio-agosto/2015 
Os depoimentos das mulheres revelam o despreparo dos profissionais, que não realizam uma escuta humanizada e, ao contrário de propiciarem acolhimento, aparentam descaso, indiferença e/ou omissão diante das situações denunciadas. Algumas juízas ainda conduzem as audiências de modo a promover a reconciliação do casal, respaldadas em valores patriarcais que limitam a questão da violência à esfera privada e naturalizam a desigualdade de poder presente no seio familiar. O que as faz classificar a violência como um problema secundário que pode facilmente ser solucionado no âmbito privado, pelo próprio casal ou através do apoio de psicólogos ou assistentes sociais, sem necessidade de perturbar o bom andamento dos tribunais, o que resulta, de acordo com Guita Grin Debert e Maria Filomena Gregori, ${ }^{18}$ na impunidade dos agressores. Deste modo, as operadoras do direito, durante as audiências, relevam a violência denunciada pelas mulheres e, ancoradas no ethos do amor romântico, costumam acionar os papéis sociais tradicionais atribuídos a homens e mulheres para reafirmar e preservar a imagem idealizada da instituição familiar e do matrimônio, tendo em vista promover a conciliação e reaproximação dos casais.

Além disso, cabe destacar que, pelo fato de existirem apenas duas DEAMs e somente uma Vara Especializada de Violência Doméstica e Familiar contra a Mulher em Salvador, uma cidade com uma população feminina de 7.138.640, conforme dados censitários do IBGE (2010), isso certamente afeta a eficiência dos serviços e, quando associado aos trâmites burocráticos, à rotatividade e ao número reduzido de funcionários, favorece a morosidade no atendimento, ao mesmo tempo em que contribui para a prescrição ou extravio de processos.

As mulheres também se queixam da falta de orientação acerca dos trâmites relativos aos processos, da falta de resolutividade e articulação entre os serviços, da demora no agendamento de audiências, e também de sua antecipação ou adiamento sem aviso prévio, além da dificuldade para concessão de medida protetiva e da ausência de providências diante do seu descumprimento pelos agressores. Conforme ressalta o depoimento abaixo:

Com relação ao Ministério Público, o único entrave que eu vi até hoje é a parte burocrática, que o inquérito sai da DEAM para chegar até a Vara, é um descalabro. A gente ter que passar por uma Central de Inquérito, demorar séculos até ser arquivado ou então a gente tem que procurar testemunhas, que normalmente a gente não tem a testemunha real do que acontece entre quatro paredes, para poder um representante do Ministério Público receber a denúncia, a não ser que seja uma coisa explícita na rua. Então, nós perdemos muito tempo esperando que o inquérito seja finalizado e recebido pelo Ministério Público até chegar à Vara. Afora isso, o Ministério Público faz seu papel, como autor da ação penal, mas infelizmente a justiça é um elo, ela precisa do cartório, precisa do juiz, precisa do oficial de justiça, do defensor público, e aí nada anda, eu me sinto hoje esmolando justiça. (Irene)

Ao refletir sobre o papel a ser desempenhado pelo Ministério Público (MP), Sérgio Ricardo de Souza ${ }^{19}$ considera que a intervenção do MP tem como finalidade proteger os interesses sociais e individuais indisponíveis, em especial, a dignidade da mulher em situação de violência e atua, na maioria das vezes, como fiscal da Lei.

Em dezembro de 2006, o MP da Bahia criou o Grupo de Atuação Especial em Defesa da Mulher (Gedem), cuja atuação estende-se desde a ocorrência de crimes até a prevenção e disseminação do conhecimento acerca da violência de gênero e a Lei Maria da Penha, o que tem contribuído para promover o aumento de denúncias e um atendimento mais

${ }^{18}$ Guita Grin DEBERT e Maria Filomena GREGORI, 2008.

19 Sérgio Ricardo de SOUZA, 2013. 
qualificado às mulheres.$^{20}$ No entanto, cabe ressaltar que, sem uma ação orquestrada com as DEAMs e demais serviços da Rede, o Gedem não consegue garantir a proteção e a assistência integral às mulheres em situação de violência doméstica e familiar.

De fato, o depoimento de Irene revela que, nas DEAMs de Salvador, a hierarquia, a falta de comunicação entre os setores e os trâmites legais afetam o fluxo de atendimento, o que contraria os princípios de celeridade e de acesso à justiça defendidos pela Lei no 1 1.340. Mais precisamente, com relação aos procedimentos penais e processuais penais estabelecidos no artigo 12 da Lei, cujo inciso III determina o prazo de 48 horas para remeter a juiz/juíza o pedido da ofendida relativo à concessão de medidas protetivas de urgência e, no inciso VIl, encaminhar, no prazo legal, os autos do inquérito policial a juiz/juíza e ao Ministério Público. ${ }^{21}$

Em documento enviado pela Defensoria Pública da Bahia à Comissão Parlamentar Mista de Inquérito (CPMI), para composição do dossiê $A$ Bahia e a violência contra mulheres, ${ }^{22}$ a Defensora Pública Geral reconhece que a Defensoria Pública da Bahia não promove o atendimento especializado, integral e interdisciplinar previsto pela Lei Maria da Penha, em virtude do número insuficiente de defensores e de servidores auxiliares. O quadro funcional é composto por 202 defensores públicos, dos quais 134 atuam na capital.

Cabe registrar que em Salvador existe apenas um Núcleo de Atendimento às Mulheres Vítimas de Violência Doméstica e Familiar (Nudem). A equipe do Nudem, conforme consta no dossiê da CPMI na Bahia, conta com uma defensora pública, que exerce a função de coordenadora do Núcleo e é responsável por grande parte do atendimento inicial. Uma outra que atua na Vara, prestando assistência jurídica às mulheres, além de duas servidoras administrativas, quatro estagiários de Direito, duas estagiárias do bacharelado em Gênero da Universidade Federal da Bahia e duas estagiárias de ensino médio.

As mulheres também declaram que são intimidadas para não denunciarem na Ouvidoria as inadequações no atendimento, o descaso e o descumprimento da medida protetiva, conforme ilustram os seguintes depoimentos:

[...] a juíza foi a advogada dele [...] liberou ele e revogou a medida protetiva. Quando eu fui dar uma queixa na Ouvidoria por causa disso, do ato da juíza, o ouvidor, Sr. X., me disse o seguinte - 'eu vou ligar para a Vara agora, a juíza vai resolver isso'. Aí voltou, eu disse - 'sim, mas eu quero deixar registrado de que aconteceu isso'. 'Olha, se a senhora registrar, o que vai acontecer, até quarta-feira ela resolve, já liguei para lá. Se a senhora registrar, a senhora não vai ver nem quarta, nem daqui a três meses, nem daqui a um ano, nada resolvido, porque isso é sério o que a senhora está fazendo contra a juíza'. (Érica)

Meu processo estava para prescrever em maio, eu nunca corri tanto, eu nunca adoeci tanto, eu nunca perdi tanto. Eu fui para a Corregedoria, eu fui para a Ouvidoria eu fui para o Tribunal, eu fui para a Assembleia, até e-mail para o CNJ eu mandei. Qual foi a consequência que eu arquei e estou arcando com isso, sozinha? Um malestar na Vara, eu já estou com o quinto juiz [...], que meu processo sexta-feira foi parar na $2^{a}$ Vara da Infância, que foram várias substituições. Juiz se dando por suspeito, informações desencontradas, e é a palavra de um magistrado contra a minha, de uma vítima. A princípio, tanto pelo réu como pela justiça, queriam me taxar de desequilibrada emocional. (Irene)

${ }^{20}$ De acordo com dados fornecidos pelo MP à Comissão da CPMI na Bahia (2012), em 2006, quando o Gedem foi criado, a capital oferecia em média 147 denúncias e, em 2012, o número subiu para cerca de 2 mil denúncias. A equipe psicossocial do Gedem realiza visitas hospitalares, palestras, oficinas e eventos, além de acompanhar mulheres que enfrentam dificuldades (indicativo de interrupção de gravidez) entre outras ações. ${ }^{21}$ BRASIL, 2006.

554 Estudos Feministas, Florianópolis, 23(2): 547-559, maio-agosto/2015 
Apesar da crescente feminização do Judiciário, as desigualdades de gênero persistem na magistratura, que permanece um espaço gendrado, masculino, o que interfere na postura de juízas, delegadas e promotoras, cuja aceitação entre os pares parece estar condicionada à negação de sua identidade feminina. Assim, na tentativa de imprimirem racionalidade e objetividade às sentenças formuladas, adotam uma postura mais rígida, que associam ao sexo masculino. Por outro lado, podem se deixar seduzir pelo poder opressor e estabelecer uma identificação com aquelas figuras que, até então, consideravam dominadoras, o que se reflete no seu desinteresse pelos conflitos domésticos e pelas reivindicações femininas. ${ }^{23}$

Por outro lado, a intimidação é um recurso comumente utilizado tanto para demarcar como para reforçar a subordinação de gênero, podendo causar diferentes reações nas mulheres em situação de violência, desde inércia e resignação até revolta e indignação. Todavia, prevalece o sentimento de impotência, na medida em que o acesso à justiça deixa de ser direito adquirido e se transforma em concessão, quando a agilidade do procedimento jurídico fica à mercê da disponibilidade e/ou "boa vontade" dos operadores da lei.

Além disso, a demora em encaminhar as mulheres ao atendimento psicossocial, assim como a realização de perícias inadequadas e descuidadas no IML ou mesmo a pouca compreensão dos profissionais sobre as modalidades de violência que atingem as mulheres, afetam o atendimento e indicam descumprimento e/ou desconhecimento da Lei Maria da Penha.

\begin{abstract}
Aí eu fui no IML, fiquei a madrugada toda no IML. Quando foi de manhã meu carro foi periciado, eu não fui periciada. E aí eu voltei para a delegacia. Dei a perícia do carro, marcaram minha audiência para mais de três meses depois. [...] Aí, o que aconteceu, voltei no IML, para fazer meu exame, meu rosto ficou [estava] preto, tudo embaixo [dos olhos] preto, horrivel [...]. A pessoa via que eu tinha sido agredida [...]. Ela veio fazer meu exame, e eu pedi que ela tirasse foto, ela disse que não era necessário. [...] Por que o IML não manda a gente fazer um exame aprofundado? Por que não tirou fotos? Por que não mandou fazer uma revisão depois, daqui a 15 dias: 'vamos ver esses olhos como é que estão', né? (Érica)
\end{abstract}

Eu ouvi por diversas vezes na Vara que eu estava me fazendo de vítima, por quê? Porque naquele momento eu não cheguei lá com o rosto quebrado, ensanguentada, roxa ou morta. Porque quando a gente chega a esse ponto, as providências são mais rápidas, até porque o caso se torna mais público. (Irene)

Esses depoimentos revelam um problema já identificado em outras pesquisas realizadas pelo Observe: os profissionais dos serviços parecem não ter passado por formação específica sobre a questão de gênero e a violência doméstica. Deste modo, para que a violência seja caracterizada como tal, a mulher deve apresentar uma prova inconteste marcas visíveis como hematomas, machucados etc. -, enquanto maus tratos, humilhações, entre outras formas de violência, cujas ranhuras na autoestima feminina revelam-se internamente, continuam a ser ignorados.

Conforme já mencionado, as solicitações de medidas protetivas encaminhadas pelas DEAMs à Vara Especial não vêm sendo concedidas pelas/os magistrada/os no prazo de 48 horas, conforme prescreve a Lei Maria da Penha. Levam em torno de seis meses a um ano para serem decretadas e cumpridas, conforme comprovado durante a visita da

${ }^{22}$ A BAHIA E A VIOLÊNCIA CONTRA MULHERES, 2012.

${ }^{23}$ TAVARES, SARDENBERG e GOMES, 2011. 
Comissão da CPMI à Vara. Ocasião em que encontramos uma mulher que aguardava a medida protetiva fazia um ano e teria o primeiro atendimento psicossocial naquele dia: ${ }^{24}$

[...] e quase um ano depois eu continuo na mesma situação. Nada mudou, ele bebe e vai na minha casa, continua me agredindo [...]. Procuro saber como tá o processo, chego aqui e dizem que está na mesa da juíza, mas que ela ainda não deu o parecer [...]. Eu esperava que a medida protetiva saísse no máximo em uns vinte dias, em dez dias [...]. Dizem que é assim mesmo, tem que esperar. Aí volto pra casa, espero uns quinze dias, dez dias, retorno [...]. O medo permanente e a exposição a situações de risco, apesar de ter buscado os serviços e a ausência pronta de socorro... (Tina)

A implantação da Vara de Violência Doméstica e Familiar contra a mulher, em Salvador ocorreu em 2008 e, na ocasião, foi formada uma equipe multidisciplinar de dez profissionais (cinco psicólogas e cinco assistentes sociais), a qual foi destituída em 2010 , em virtude do regime de contratação temporária (Regime de Administração Direta-REDA). Para suprir a ausência desse atendimento, o Tribunal de Justiça da Bahia transferiu a competência para as equipes multidisciplinares que atuam junto às Varas de Família, a despeito das reações contrárias da rede e do movimento de mulheres local. ${ }^{25}$

De fato, durante a CPMI, em 2012, identificou-se a desarticulação do serviço, restando apenas uma psicóloga para responder a cerca de 9.500 ações penais em curso. ${ }^{26}$ Consequentemente, vários projetos foram interrompidos, o vínculo estabelecido entre as mulheres assistidas e a equipe de profissionais foi rompido de forma abrupta, oficinas de apoio às mulheres e de reeducação de homens agressores foram suspensas e, como não há previsão de concurso público, a permanência da equipe é uma incógnita, pode ser desligada daqui a dois ou quatro anos, ou exonerada quando ocorrer a mudança da titular do órgão, que acontece regularmente a cada dois anos. ${ }^{27}$

No tocante ao Instituto Médico Legal, os depoimentos também indicam a necessidade de capacitação permanente dos servidores sobre as relações de gênero, a violência contra a mulher e a Lei Maria da Penha. Bem como a implantação de um serviço especializado de perícia para mulheres em situação de violência, dotado de um ambiente humanizado e acolhedor, ${ }^{28}$ no qual se sintam respeitadas e não tratadas com descaso, indiferença e, tantas vezes, com rispidez e impaciência, como se "estivessem se fazendo de vítimas", querendo apenas chamar a atenção.

As mulheres reportam-se ainda à Casa de Acolhimento, ${ }^{29}$ integrante da estrutura dos serviços de atenção de alta complexidade do Sistema Único de Assistência Social (SUAS), vinculada à Secretaria de Assistência Social e Combate à Pobreza, instituição que, de acordo com os depoimentos, parece não conseguir contemplar as especificidades do fenômeno da violência de gênero, principalmente em sua modalidade doméstica e/ou familiar, nem tampouco atender as necessidades concretas das mulheres em situação de

\footnotetext{
${ }^{24} \mathrm{~A}$ ida da Comissão à Vara não foi programada e a juíza estava ausente, mas, avisada pelos funcionários, retornou quando a equipe entrevistava Tina e, após tomar conhecimento do caso, imediatamente emitiu a medida protetiva.

${ }^{25}$ Wânia PASINATO, SARDENBERG e GOMES, 2010

26 Conforme o dossiê da CPMI (A BAHIA E A VIOLÊNCIA CONTRA MULHERES, 2012), diante das constantes reclamações, durante o ano de 2011 , foi realizada uma avaliação/correição da Vara de Salvador, mas apesar de solicitar o documento ao presidente do Tribunal de Justiça, a comissão não teve acesso ao mesmo. 27 SENADO FEDERAL, 2013.

28 SENADO FEDERAL, 2013

${ }^{29} \mathrm{~A}$ Casa de Acolhimento, com capacidade para abrigar 15 mulheres e 60 crianças, é integrada organicamente às Políticas Nacionais de Assistência Social e de Abrigamento, que apoiam e complementam a Política de Enfrentamento à Violência contra a Mulher.
}

556 Estudos Feministas, Florianópolis, 23(2): 547-559, maio-agosto/2015 
violência que a ela recorrem. A Casa é descrita pelas mulheres como mais uma violência, um espaço em que se sentem punidas em lugar do agressor, já que são elas e não eles que são presos. Assim, saem do cárcere privado para serem novamente aprisionadas nas instituições de abrigamento: "Lá eu me sentia prisioneira, às vezes a gente não podia nem sair para tomar sol..." (Lívia).

Todavia, se as mulheres sentem-se desprotegidas, desassistidas, aprisionadas ou mesmo intimidadas nesses serviços, o mesmo não acontece no Centro de Referência Loreta Valadares. Criado desde 2005, é lugar onde encontram apoio e se sentem compelidas a soltar a voz e a expressar seus temores, inseguranças, necessidades e sonhos: "Porque lá nós somos tratadas [...] com dedicação, com atenção, com respeito e com muito cuidado" (Marta). Ou seja, ali recebem assistência psicológica, jurídica e social que as conforta e fortalece para recomeçarem suas vidas sem violência.

\section{Arremate}

Nos depoimentos aqui reunidos, traduzi o desencantamento e a descrença das mulheres em situação de violência doméstica e familiar com a rede de proteção social. Suas narrativas falam de solidão, mágoa e impotência diante do descumprimento da Lei $\mathrm{n}^{\circ} 11.340$, dos serviços e profissionais que ainda tratam a violência doméstica e familiar como um assunto de ordem privada e que, portanto, deve ser resolvido pelo casal, entre quatro paredes, sem a interferência de agentes, peritos, delegadas e juízas, que têm tarefas mais importantes. Sem serem ouvidas, as mulheres sentem-se desrespeitadas, humilhadas, desassistidas e temerosas: "Eu estou vendo a hora de eu morrer, porque fui, passei por tudo isso e não resolveu nada" (Irene).

Enfim, as mulheres consideram que não encontram na rede de atendimento o acolhimento e a proteção de que necessitam, pois são culpabilizadas pela situação de violência e tratadas como rés. A forma como são atendidas, isto é, a morosidade, o descaso e a indiferença com que são tratadas, rouba a sua dignidade e autoestima, ao mesmo tempo em que afeta sua saúde física e emocional.

Por essa razão, consideram o atendimento insatisfatório, tanto nas DEAMs como na Vara, no Ministério Público, no IML e até no Disque 190, classificando-os como "horríveis", uma vez que suas demandas não são atendidas e, desprotegidas, tornam-se reféns das situações de violência que as levam a peregrinar por estas instituições, em busca de justiça. Neste sentido, os serviços não são reconhecidos como direito, mas favor do qual dependem para terem acesso à justiça e à proteção social e prosseguirem com suas vidas. Em outras palavras, a agilidade e/ou resolutividade na concessão de medidas protetivas e sentenças depende das relações pessoais, do vínculo estabelecido com este/a ou aquele/ a defensor/a, juiz, juíza, caso contrário, as mulheres têm que recorrer à interferência de advogado/a contratado/a.

Ao final da Roda de Conversa, as mulheres transpareciam o desejo de que mudanças ocorram e, com força renovada, alertavam: "Não vim aqui com cara de vítima, eu sou vítima, eu não vim me fazer de vítima, eu sou vítima, estou aqui em nome de todas as mulheres para essa comissão, que eu espero não ser mais uma coisa política" (Aurora). E, num gesto cúmplice, abraçavam-se esperanças.

\section{Referências}

A BAHIA E A VIOLÊNCIA CONTRA MULHERES. Dossiê apresentado à Comissão Parlamentar Mista de Inquérito. Salvador, julho de 2012. Disponível em: http://www.senado.gov.br/comissoes/ documentos/SSCEPI/DOC\%20VCM\%20216\%2OPRINCIPAL.pdf. Acesso em: 10 jan. 2012. 
AFONSO, Maria Lúcia M.; ABADE, Flávia. Para reinventar as Rodas. Belo Horizonte: Rede de Cidadania Mateus Afonso Medeiros (Recimam), 2008.

AQUINO. Silvia de. Pathways of Women's Empowerment through Legal Strategies: the Case of Maria da Penha Law (Brazil). Brasil, 2008.

BANDEIRA, Lourdes. Fortalecimento da Secretaria Especial de Políticas para as Mulheres: avançar na transversalidade da perspectiva de gênero nas políticas públicas. Brasília: CEPAL; SPM, 2005.

BARSTED, Leila Linhares. "A resposta legislativa à violência contra as mulheres no Brasil". In: ALMEIDA, Suely (Org.). Violência de gênero. Rio de Janeiro: Editora UFRJ, 2007. p. 119-137.

BLAY, Eva Alterman. "Violência contra a mulher e políticas públicas". Estudos Avançados, v. 17, n. 49, p. 87-98, 2003. Disponível em: http://www.scielo.br/pdf/ea/v1 7n49/18398.pdf. Acesso em: 15 jun. 2010.

BRASIL. Presidência da República. Lei no 11.340, de 7 de agosto de 2006. (Lei Maria da Penha). Cria mecanismos para coibir a violência doméstica e familiar contra a mulher... Disponível em: http://www.planalto.gov.br/ccivil_03/_ato2004-2006/2006/lei/l1 1340.htm. Acesso em: 20 maio 2014.

. Pacto Nacional pelo Enfrentamento à Violência contra a Mulher. SPM Brasília, 2007. Disponível em: http://www.spm.gov.br/sobre/a-secretaria/subsecretaria-deenfrentamento-a-violencia-contra-as-mulheres/pacto/Pacto\%20Nacional. Acesso em: 18 jun. 2012.

DEBERT, Guita Grin; GREGORI, Maria Filomena. "Violência e gênero: novas propostas, velhos dilemas". Revista Brasileira de Ciências Sociais, v. 23, n. 66, p. 165-185, 2008. Disponível em: http://www.scielo.br/pdf/rbcsoc/v23n66/1 1.pdf. Acesso em: 18 jun. 2010.

GREGORI, Maria Filomena. Cenas e queixas: um estudo sobre mulheres, relações violentas e a prática feminista. Rio de Janeiro: Paz e Terra; São Paulo: Anpocs, 1993.

PASINATO, Wânia; SARDENBERG, Cecilia M. B.; GOMES, Márcia Q. de C. Condições para aplicação da Lei 11.340/2006 nas DEAMs e nos Juizados de Violência Doméstica e Familiar contra a Mulher nas capitais e no Distrito Federal. Salvador, Bahia, 2010. Relatório técnico.

PIOVESAN, Flávia; PIMENTEL, Sílvia. Lei Maria da Penha: inconstitucional não é a lei, mas a ausência dela. Brasília: Secretaria Especial de Políticas para as Mulheres, 2007.

QUEIROZ, Fernanda Marques de. Não se rima amor e dor: cenas cotidianas de violência contra a mulher. Mossoró: UERN, 2008.

SANTOS, Cecília MacDowell. "Da Delegacia da Mulher à Lei Maria da Penha: lutas feministas e políticas públicas sobre violência contra mulheres no Brasil". Revista Crítica de Ciências Sociais, Universidade de Coimbra, n. 89, p. 153-170, jun. 2010.

SARDENBERG, Cecilia; TAVARES, Márcia Santana; GOMES, Márcia Q. de C. "Feminismo e políticas públicas: monitorando a implementação da Lei Maria da Penha. In: XXX CONGRESSO DA LASA - Latin American Studies Association, 2012, San Francisco, CA. Disponível em: http://lasa.international.pitt.edu/members/congress-papers/lasa2012/files/ 26851.pdf. Acesso em: 20 ago. 2013.

SENADO FEDERAL. Comissão Parlamentar Mista de Inquérito Sobre a Violência Contra a Mulher. Relatório Final. Brasília/Senado Federal, Julho de 2013. Disponível em: http:// spm.gov.br/publicacoes-teste/publicacoes/relatorio-final. Acesso em: 14 jul. 2013.

SOUZA, Sérgio Ricardo de. Lei Maria da Penha comentada: sob a nova perspectiva dos direitos humanos. Curitiba: Juruá, 2013.

TAVARES, Márcia Santana; SARDENBERG, Cecilia; GOMES, Márcia Q. de C. "Feminismo, Estado e políticas de enfrentamento à violência contra mulheres: monitorando a Lei Maria da Penha". Labrys (Edição em português), v. 20, p. 1-30, 2011. 
[Recebido em 10 de outubro de 2014 e aceito para publicação em 5 de fevereiro de 2015]

Wheel Conversation Between Women: Complaints about the Inapplicability of the Maria da Penha Law in Salvador/BA and Disbelief in Justice

Abstract: This article discusses the challenges to the application of Law Maria da Penha in Salvador, Bahia, from the testimony of eleven women in situations of domestic violence, whose complaints and demands on the network were verbalized in a Wheel Conversation, held at the Council for the Development of the Black Community - CNDN, on 05/06/2012, for the elaboration of a dossier to be submitted to CPMI Violence during his efforts in Bahia. Women considered unsatisfactory attendance, both in DEAMs as in Vara, the prosecutor in the IML and even in Disque 190, classified as "ugly", since their demands are not met, they feel unprotected, humiliated, disrespected and , hostage situations of violence that lead them to wander by these institutions. Key Words: Violence against Women; Maria da Penha Law; Access to Justice. 